\title{
A Simplified Approach for Predicting the Time of Consolidation for a Multi-Layered Foundation
}

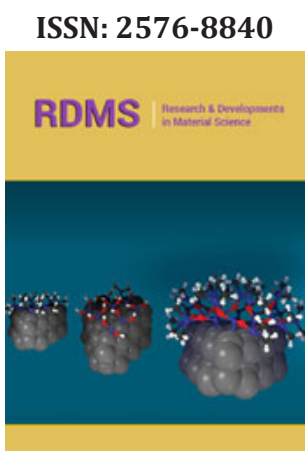

*Corresponding author: Tham H Duong, Department of Civil Engineering, Ho Chi Minh City Open University, Vietnam

Submission: 鳢 September 21, 2021

Published: 制September 28, 2021

Volume 15 - Issue 5

How to cite this article: Tham H Duong. A Simplified Approach for Predicting the Time of Consolidation for a MultiLayered Foundation. Res Dev Material Sci. 15(5). RDMS.000871. 2021 DOI: $10.31031 /$ RDMS.2021.15.000871

Copyright@ Tham H Duong.This article is distributed under the terms of the Creative Commons Attribution 4.0 International License, which permits unrestricted use and redistribution provided that the original author and source are credited.
Tham H Duong*

Department of Civil Engineering, Ho Chi Minh City Open University, Vietnam

\begin{abstract}
This paper deals with a simplified approach of predicting the time of consolidation settlement for a multilayered foundation using the coupling technique for settlement and unsettlement zones in a specific compressible layer and layers. According to MIT's lecture, every two layers should combine into one having an equivalent degree of consolidation or having an equivalent thickness of consolidation. From this valuable guideline, several procedures are developed to tackle the specific problem of the settlement of a multi-layered foundation. This study also introduces an idea for coupling the layers, concerning the drainage path during combining every two layers, and some practical points are suggested.
\end{abstract}

Keywords: Consolidation settlement; Equivalent coefficient of consolidation $\mathrm{C}_{\mathrm{v}, \mathrm{eq}}$; Thickness $\mathrm{H}_{\mathrm{eq}}$; Settlement zones

\section{Introduction}

Estimating the consolidation settlement of a layered foundation is a complicated task. In multi-layered foundation, and the rate of consolidation settlement for such a multi-layered foundation is a non-linear problem approximately solved by many research works such as: Taking the varied compressibility into account [1]; considering the variation in permeability [2]. A technique of coupling every two compressive layers into one equivalent is developed by applying MIT's suggestion [3].

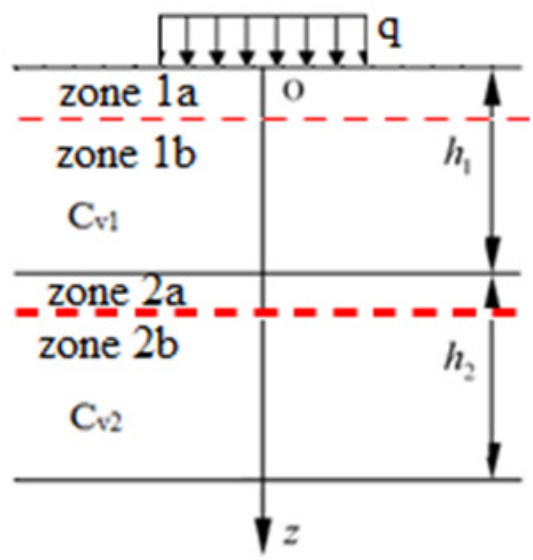

Figure 1: Settlement zones in a compressible layer.

During the time of consolidation, there are the settlement zones $1 \mathrm{a}, 2 \mathrm{a}$, and unsettled zones $1 b, 2 b$ or still zones recognized (Figure 1 ), and the compressibility of the zone of settlement (i.e., 1 a for layer 1 and 2 a for layer 2 ) has definitely varied, both in permeability 
and compressibility. By assuming that the unsettled layer (i.e., $1 \mathrm{~b}$ or $2 \mathrm{~b}$ in Figure 1) has no variation in the compressibility so that each compressible layer has two separate sub-layers (e.g., 1a and 2a of layer 1), which the coefficient of consolidation is not the same as the original values. A question is what occurs if the zone of settlement, e.g., $1 \mathrm{a}$ or $2 \mathrm{a}$, which both have changed the compressibility and the coefficient of consolidation could take into account.

This paper aims to further some results studied by $[3,4]$ investigate the consolidation settlement of the multi-layered compressible foundation, concerning the settlement zones into account.

\section{Theoretical Background}

\section{Assumptions}

a) Every multi-layered foundation has compressible layers and very low compressible layers (e.g., sand, even a thin layer). The sand layer plays the role of a drainage boundary. As a default concept, the other boundary of drainage is the ground surface. In the other words, in most possible cases, there is a pervious layer in the foundation

b) The coefficient of consolidation $\mathrm{Cv}$ is time-variant quantity, for a varied coefficient of permeability $\mathrm{k}$ as expressed in the following equation 1 :

$$
C_{V}=\frac{k}{m_{v} \gamma_{w}}
$$

c) The coefficient of volume compressibility $m_{v}$ also varies with respect to void ratio, therefore a time-variant variable.

d) Coefficient of consolidation $\mathrm{C}_{\mathrm{v}}$ will change its value within a settlement zone while being constant if outside the settlement zone (zone 1b in Figure 1).

e) Each layer has its constant characteristics of compressibility and permeability. The load is fully constructed at the start of loading, and soil is normally consolidated. The condition of equivalence is the two models have the same degree of consolidation.

f) The permeability varies only within the settled zone (i.e., zone $1 \mathrm{a}$ or $2 \mathrm{a}$ ); the coefficient of permeability k would be of 3 -order power of the void ratio, i.e. $\mathrm{k} \alpha \mathrm{e}^{3}$;

g) The Terzaghi's theory of 1-D consolidation is still valid within a compression layer.

\section{Equivalent coefficient of consolidation}

The double-layered foundation are converted to a single layer having the equivalent coefficient of consolidation from the equation

(2) without changing the thickness of the foundation (Figures $2 \&$ 3).

$$
C_{v, q}=\frac{\sum_{i=1}^{n}\left(h_{i}\right)^{2}}{\sum_{i=1}^{n}\left(\frac{h_{i}}{\sqrt{C_{\dot{v}}}}\right)^{2}}
$$

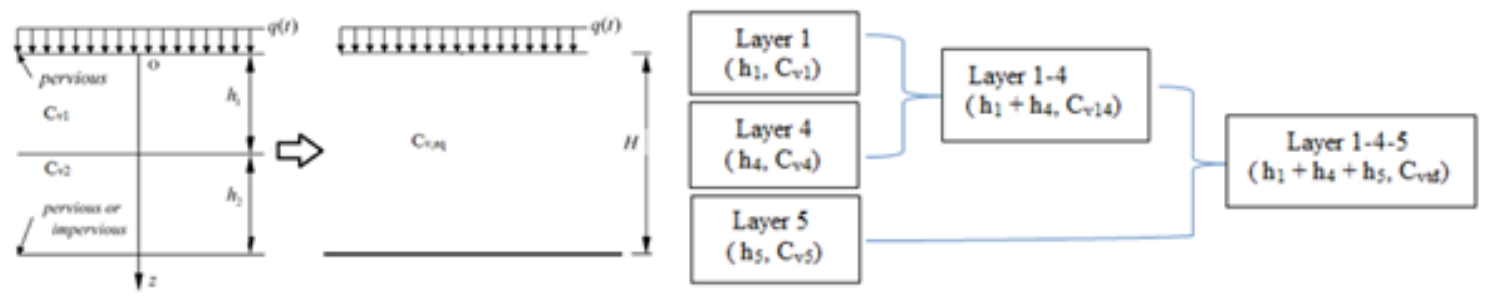

Figure 2: Concept of equivalent coefficient of consolidation $\mathrm{C}_{\mathrm{v} \text {, eq }}$.

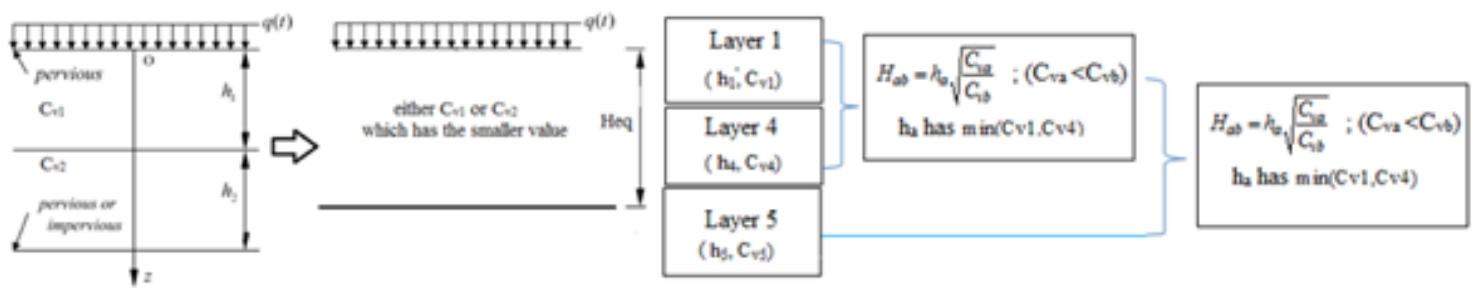

Figure 3: The equivalent depth suggested by MIT (Source: MIT's Lecture Notes).

\section{Equivalent thickness of consolidation settlement}

MIT suggested that an alternative keeps the properties as original values but changes the depth into an equivalent one having the same compressibility (the smaller value of $\mathrm{C}_{\mathrm{v}}$ is taken into account) [5].
The key assumption for the latter approach is that both the boundaries are either pervious or impervious, so that the drainage length would be $\mathrm{d}=\mathrm{H}_{\mathrm{eq}} / 2$ in which $\mathrm{H}_{\mathrm{eq}}$ is the equivalent thickness of the converted two-layer foundation. 


$$
H_{q 1}=h_{1} \sqrt{\frac{C_{v 1}}{C_{v 2}}}+h_{2}
$$

where $h_{1}$ are the thickness having the smaller value of the coefficient of consolidation, or $\mathrm{C}_{\mathrm{v} 1} \cdot \mathrm{H}_{\mathrm{eq}}$ then is the equivalent thickness of the foundation that has the greater value of the coefficient of consolidation $\mathrm{C}_{\mathrm{v} 2}$.

\section{A simplified model for estimating the degree of consolidation}

Fine-grain soil as clay would be assumed to be timedependently compressible, while non-cohesive soil like sand will not be compressible. The multi-layered foundation with stratums are described in Figure 4:

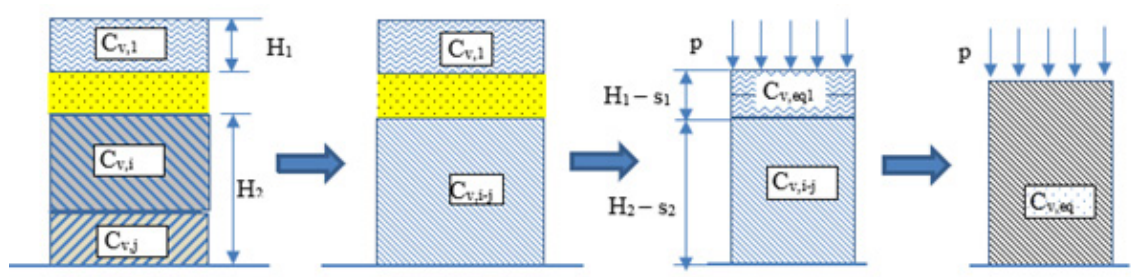

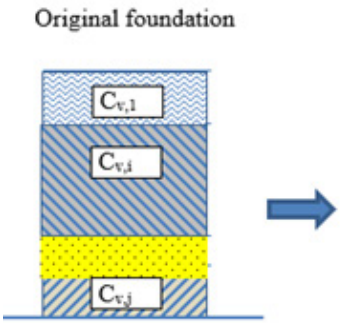

Original foundation

Pattern 1: Lower layers combined
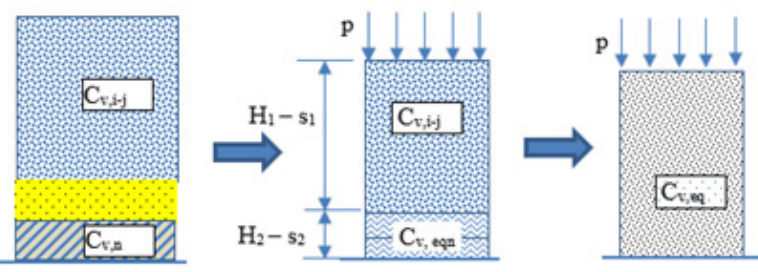

Pattern 2: Upper layers combined

Figure 4: Two possible cases for the consolidation settlement, estimated by the formulas 2 .

In each layer, the settlement, denoted s1 or s2, is easily predictable as the accumulated vertical deformation over the total thickness of the layer, and then there is an unsettlement zone beneath the settlement zone in this layer, $\left(\mathrm{H}_{1}-\mathrm{s}_{1}\right)$ or $\left(\mathrm{H}_{2}-\mathrm{S}_{2}\right)$ as in Figure 4. $\mathrm{C}_{\mathrm{v}, \mathrm{eq} 1}$ is the equivalent coefficient of consolidation combining the compressibility of sub-layer s1, and the unsettlement zone $\left(\mathrm{H}_{1}-\mathrm{s}_{1}\right)$ having original $\mathrm{C}_{\mathrm{v}, 1} ; \mathrm{C}_{\mathrm{v}, \mathrm{i}-\mathrm{j}}$ is of the combined lower compressible layers. These equivalent converted layers with sublayers take into account the boundaries of drainage. There are two main patterns of combination: lower and upper equivalent layers which are open layers in the upper part and half-open in the lower part of the foundation. Pattern 1 has the coupled lower conversion, whilst pattern 2 has the upper conversion [6].

The time of consolidation for the two possible cases is mainly different due to the drainage condition, i.e. the length of drainage $\mathrm{d}$ and the effective normal stress in layers. This concern points out that formula (2) using the coefficient of consolidation $\mathrm{C}_{\mathrm{v}}$ in prediction is more practicable and reasonable than formula (3) with $\mathrm{H}_{\mathrm{eq}}$.

Table 1: Soil layers in this study.
The degree of consolidation, $\mathrm{U}(\%)$ could be estimated by formula $4 \mathrm{a}$ and $4 \mathrm{~b}$, as below:

$$
\begin{aligned}
& T_{v}=\frac{\pi}{4}\left(\frac{U}{100}\right)^{2} \text { for short term, } T_{v}<0.1 \\
& T_{v}=-0.0851-0.933 \log (1-U)
\end{aligned}
$$$$
T_{v}>0.1 \text { or } U>60 \%
$$

for long term,

where $T_{v}$ is the dimensionless time factor, determined by the formula $T_{v}=C v, e q \frac{t}{d^{2}}$, in which $\mathrm{d}$ is the drainage length in each layer, and $t$ is the time of consolidation.

\section{A model for validation}

The equivalent coefficient $\mathrm{C}_{\mathrm{v}, \mathrm{eq}}$ and the equivalent thickness $\mathrm{H}_{\mathrm{eq}}$ are calculated by the formula (2) and (3). The following model

\begin{tabular}{|c|c|c|c|c|c|c|}
\hline No & $\begin{array}{l}\text { Depth of } \\
\text { Sampling }\end{array}$ & Void Ratio e & $\begin{array}{l}\begin{array}{c}\text { Coefficient of } \\
\text { Consolidation } C_{v 90} \\
\left(\mathrm{~cm}^{2} / \mathrm{s}\right) \times 10^{-3} \mathbf{P}_{5-6}\end{array}\end{array}$ & $\begin{array}{l}\text { Compression } \\
\text { Index Cc }\end{array}$ & $\begin{array}{l}\text { Preconsolidation } \\
\text { Pressure Kpa }\end{array}$ & Description \\
\hline 1 & 2 & 3 & 4 & 5 & 6 & 7 \\
\hline 1 & $1.8-22$ & 2.686 & 0.328 & 1.494 & 67.3 & $\begin{array}{c}\text { Clay mud, liquid } \\
\text { state. }\end{array}$ \\
\hline
\end{tabular}
will apply it in calculating the consolidation, concerning the compressibility of settlement zones. 


\begin{tabular}{|c|c|c|c|c|c|}
\hline 2 & $22.4-24$ & 2.754 & 0.215 & 1.322 & Mud, liquid state. \\
\hline 3 & $29.8-30$ & 0.6 & 0.457 & 0.126 & $\begin{array}{c}\text { Brownish Clay, } \\
\text { Stiff. }\end{array}$ \\
\hline 4 & $37.8-38$ & 0.506 & 0.487 & 0.09 & $\begin{array}{c}\text { Sandy Clay, plastic } \\
\text { stiff. }\end{array}$ \\
\hline 5 & $39.8-40$ & 0.511 & 0.467 & 0.102 & Clayey, semi-stiff. \\
\hline
\end{tabular}

Real soft soil properties at a real site in District 2 Ho Chi Minh City (a typically soft soil foundation) are reviewed as in Table 1. As per the Terzaghi's assumption for the case in which the loading width extends to infinity or very large as compared to the thickness of compressible layer, the 1D consolidation is applicable. The site subjected a 1D consolidation with total stress $32 \mathrm{kPa}$ over a very wide area (nearly 2 meters backfill height over very soft soil foundation, spreading over a very wide area of backfilling) (Figures 5 \& 6).

Data are input into the Plaxis 2D model using Mohr Coulomb model, with drained mode for consolidation analysis.

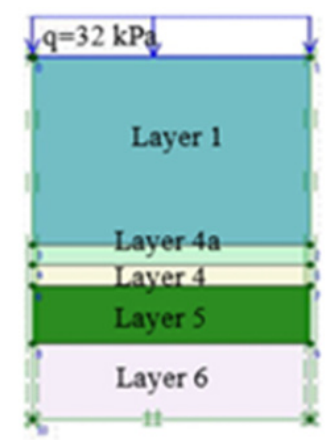

Figure 5: Plaxis model.
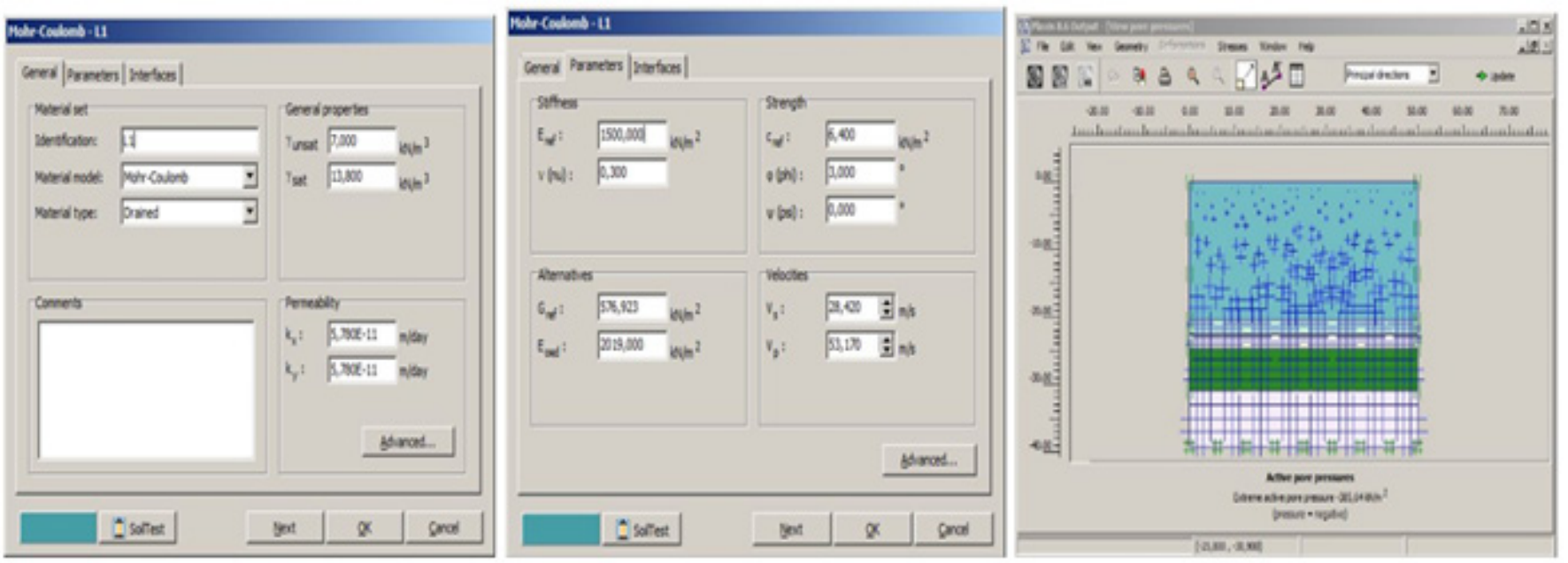

Figure 6: Input data for 1D Consolidation Analysis using Plaxis 2D for comparison purpose.

\section{Consolidation settlement}

Table 2: Soil properties and total consolidation settlement.

\begin{tabular}{|c|c|c|c|c|c|c|c|}
\hline \multirow{2}{*}{ Layer } & \multirow{2}{*}{ Level } & Thickness & $\gamma_{\text {sat }}$ & C & $\varphi$ & $\mathbf{E}$ & \multirow{2}{*}{$\begin{array}{l}\text { Settlement } \\
(\mathrm{mm})\end{array}$} \\
\hline & & (m) & $\left(\mathrm{kN} / \mathrm{m}^{3}\right)$ & (kPa) & (o) & (kPa) & \\
\hline $1+2$ & $\begin{array}{c}\text { Ele. }-1.8 \text { to Ele. } \\
22\end{array}$ & 22.4 & 13.8 & 6.4 & 3 & 1500 & 139.34 \\
\hline 4 & $\begin{array}{c}\text { Ele. }-29.8 \text { to Ele. } \\
-32\end{array}$ & 2.2 & 20.8 & 41.2 & 15 & 2800 & 11,2 \\
\hline 5 & $\begin{array}{l}\text { Ele. }-33.8 \text { to } \\
\quad-40.0\end{array}$ & 6.2 & 21.6 & 16.7 & 13 & 5200 & 22,8 \\
\hline Total & & & & & & & $173.34 \mathrm{~mm}$ \\
\hline
\end{tabular}

Under the overburden pressure $\mathrm{p}_{\mathrm{o}}\left(\mathrm{e} . \mathrm{g}\right.$ layer $\left.1, \mathrm{p}_{\mathrm{o}}=43.4 \mathrm{kPa}\right)$ and additional pressure $\Delta \mathrm{p}=32 \mathrm{kPa}$, with properties and soil stiffness, the total settlement calculated and described in Table 2 .

\section{Equivalent coefficient $\mathrm{C}_{\mathrm{v}, \mathrm{eq}}$ and thickness $\mathbf{H}_{\mathrm{eq}}$}

Case 1: Taking settlement zone 1a, 2a (Figure 1) into account, calculating the equivalent coefficient of consolidation $\mathrm{C}_{\mathrm{v}, \mathrm{eq}}$. 
Case 2: In each layer, the settlement zone and the rest part (unsettlement zone) will be converted to a new layer and so on.

\section{Comparative Results of Consolidation Settlement}

According to the results of the abovementioned convert in Table 3, the time-dependent settlement could be computed by
Terzaghi's theory of 1D consolidation, results are described in Table 4. A finite element model is created with Plaxis 2D V.8.5 as in Figure 2, with Mohr-Coulomb model of analysis for comparison purpose. The Plaxis output of the vertical displacement is shown in Figure $4 \mathrm{a}$ and the time-dependent settlement of consolidation is plotted as in Figure $4 b$.

Table 3: Equivalent values of coefficient of consolidation $\mathrm{C}_{\mathrm{v}, \mathrm{eq}}$ and thickness $\mathrm{H}_{\mathrm{eq}}$.

\begin{tabular}{|c|c|c|c|c|c|c|c|c|}
\hline \multirow[b]{2}{*}{ Layer } & \multirow[b]{2}{*}{ Parameter } & & \multicolumn{3}{|c|}{ Case 1: Equivalent Coefficient $C_{v, e q}$} & \multicolumn{3}{|c|}{ Case 2: Equivalent Thickness $\mathrm{H}_{\mathrm{eq}}$} \\
\hline & & & $C_{v, e q}$ & $C_{v, e q}$ & $\begin{array}{l}\text { Thickness } \\
\text { (m) }\end{array}$ & H & $\mathbf{H}_{\text {eq }}$ & $\mathrm{Cv}\left(\mathrm{cm}^{2} / \mathrm{s}\right)$ \\
\hline \multirow[t]{3}{*}{1} & Thickness (m) & 22.4 & & & & & & \\
\hline & $\mathrm{C}_{\mathrm{v}}\left(\mathrm{cm}^{2} / \mathrm{s}\right)$ & $3.28 \mathrm{E}-04$ & & & & & 26.59 & \\
\hline & This study & $3.27 \mathrm{E}-04$ & $3.26 \mathrm{E}-04$ & & & 24.59 & 26.86 & \\
\hline \multirow[t]{3}{*}{4} & Thickness (m) & 2.2 & $3.27 \mathrm{E}-04$ & & & 24.54 & & \\
\hline & $\mathrm{C}_{\mathrm{v}}\left(\mathrm{cm}^{2} / \mathrm{s}\right)$ & $3.27 \mathrm{E}-04$ & & $3.32 \mathrm{E}-04$ & 30.8 & & & $3.28 \mathrm{E}-04$ \\
\hline & This study & 3.11E-04 & & $3.32 \mathrm{E}-04$ & & & & $3.27 \mathrm{E}-04$ \\
\hline \multirow[t]{3}{*}{5} & Thickness (m) & 6.2 & & & & 6.2 & & \\
\hline & $\mathrm{C}_{\mathrm{v}}\left(\mathrm{cm}^{2} / \mathrm{s}\right)$ & $4.77 \mathrm{E}-04$ & 4.77E-04 & & & & & \\
\hline & This study & 4.61E-04 & 4.61E-04 & & & & & \\
\hline
\end{tabular}

Table 4: Consolidation settlement up to 500 days (settlement in $\mathrm{cm}$ ).

\begin{tabular}{|c|c|c|c|c|c|}
\hline Time (Days) & By C $_{\mathrm{v}, \mathrm{eq}}$ & $\begin{array}{c}\text { This Study (Adjusted } \\
\mathbf{C}_{\mathrm{v}, \mathrm{eq}}\end{array}$ & $\mathbf{B y}_{\mathrm{eq}}$ & $\begin{array}{c}\text { This Study (Adjusted } \\
\mathbf{H}_{\mathrm{eq}} \text { ) }\end{array}$ & $\begin{array}{c}\text { By Numerical Model } \\
\text { (Plaxis) }\end{array}$ \\
\hline 0 & 0 & 0 & 0 & 0 & 7.8 \\
\hline 100 & 4.218 & 6.8 & 4.972 & 11 & 7.5 \\
\hline 200 & 7.607 & 9.6 & 8.109 & 13.4 & 9.5 \\
\hline 300 & 9.013 & 11.8 & 9.766 & 15.5 & 11.5 \\
\hline 400 & 10.419 & 13.6 & 11.424 & 17.3 & 13.6 \\
\hline
\end{tabular}

\section{Discussion}

a) Results obtained by numerical model Plaxis 2D used the update meshing for large strain indicate a nearly perfect 1-dimension consolidation (c.f Figure 7a \& 7b).

b) It is tentatively recognized that coupling the layers concerning the settlement zones might result in a greater value of consolidation settlement; the converted foundation which uses the equivalent $C_{v \text {, eq }}$ agrees with the results given by the numerical model, i.e Plaxis ${ }^{\odot}$, and predicts a longer time of consolidation. As such it is on the safer side for warning purposes.

c) The degree of consolidation might be different between the two approaches of equivalent foundation, especially when the soil layers are highly compressible, the soft soil layers are thick and the technique of equivalent coefficient of consolidation should be studied with care. 

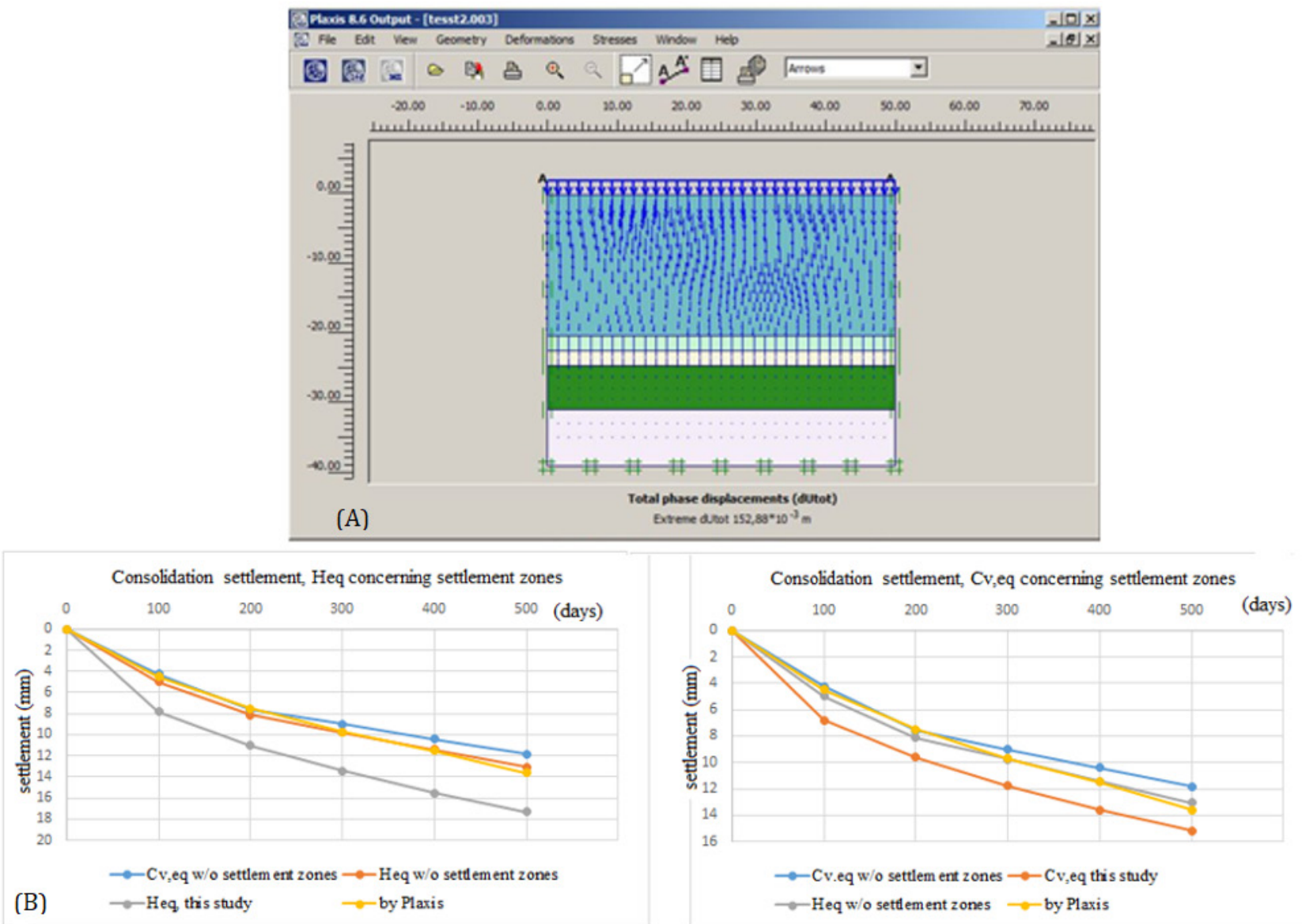

Figure 7: 1D consolidation with vertical deformation and results of time-dependent settlement with/without concerning settlement zones.

\section{Conclusion}

Consolidation settlement could be approximately estimated by using an equivalent coefficient of consolidation or equivalent thickness of compressible layers according to MIT's approximation. This study suggests every two layers will be coupled to convert them into one single and the settled zone may be viewed as a layer having varied compressibility. An equivalent foundation should use the equivalent coefficient of consolidation $\mathrm{C}_{\mathrm{v}, \mathrm{eq}}$ instead of the equivalent thickness $\mathrm{H}_{\mathrm{eq}}$ for a safer prediction. This idea of this study which takes the settlement zone into account and the equivalent coefficient of consolidation should be studied further for predicting the time-dependent settlement in the long term.

\section{References}

1. Miao L, Wang X, Kavazanjian EJ (2008) Consolidation of a doublelayered compressible foundation partially penetrated by deep mixed columns. Journal of Geotechnical and Geoenvironmental Engineering 134(8): 1210-1214.
2. Abbasi N, Rahimi H, Javadi AA, Fakher A (2006) Finite difference approach for consolidation with variable compressibility and permeability. Computers and Geotechnics 34(1): 41-52.

3. Duong T, Tu CT, Nguyen TT, Le HQ, Nguyen AHT (2020) Consolidation settlement for double layered foundation using the equivalent coefficient of consolidation and the equivalent foundation. Proceedings of the International Conference on Recent Trends in Construction Engineering and Education RTGEE, Indonesia.

4. Tham DH (2021) Studying the consolidation settlement for multilayered foundation concerning the change in compressibility within the settlement zones. Ho Chi Minh City Open University Journal of Science 11(1): 79-88.

5. Xie KG, Xie XY, Jiang W (2002) A study on one-dimension nonlinear consolidation of double layered soil. Computers and Geotechnics 29: 151-168.

6. MIT Lecture Notes CCL 11/29/83 Part V-3 Layer system. Pp. 361-366. 